\title{
Quais as contribuições do licenciado em dança na iniciação e formação artística de crianças, jovens e adultos nos estúdios, academias e companhias de dança?
}

What are the contributions of the licensee in dance in the initiation and artistic training of children, youth and adults in the studios, academies and dance companies?

Elisabeth Bauch Zimmermann ${ }^{1}$ Ayesha Zangaro ${ }^{2}$ Gisele V. Bellini ${ }^{3}$

Sabrina Barros ${ }^{4}$

\section{Resumo}

Este trabalho pretende propor reflexões que ressaltem a importância e as contribuições do bacharel e do licenciado em Dança pela Universidade no ambiente de ensino não formal das academias e companhias de dança. A partir disso, mostramos suas possibilidades de ação, levando em conta a formação que tem (o licenciado) dentro da Universidade como um condutor de metodologia, conteúdo, prioridades e filosofia de ensino.

Palavras-chave: Ensino de dança. Formação do licenciado. Academias de dança. Sapateado. Jazz dance.

\footnotetext{
1 Universidade Estadual de Campinas. Professora do Programa de Pós-Graduação em Artes da Cena e dos Cursos de Bacharelado e Licenciatura em Dança. ORCID: https://orcid.org/0000-0003-11640719 Contato: zimmandrade@gmail.com

2 Bacharel e Licenciada em Dança pela Universidade Estadual de Campinas. ORCID: https:// orcid.org/0000-0002-7873-6646 Contato: ayeshazangaro@hotmail.com

3 Bacharel e Licenciada em Dança pela Universidade Estadual de Campinas. ORCID: https://orcid.org/0000-0002-2020-7186 Contato: gii_bellinii@hotmail.com

4 Bacharel e Licenciada em Dança pela Universidade Estadual de Campinas. ORCID: https://orcid.org/0000-0001-9312-6689 Contato: sacostabarros@gmail.com
} 
Conceição | Conception

Revista do Programa de Pós-Graduação em Artes da

Cena, Universidade Estadual de Campinas

Performing Arts Graduate Program Journal, University of

Campinas

\section{Abstract}

This paper intends to propose reflections that highlight the importance and contributions of the bachelor and licensee in Dance by the University in the nonformal teaching environment of the dance academies and companies. From this we show its possibilities of action, taking into account the training that has (the licensee) within the University as a driver of methodology, content, priorities and teaching philosophy.

Keywords: Dance teaching. Licensee education. Dance academies. Tap dance. Jazz dance.

O ensino da arte por muito tempo esteve nas mãos de instituições particulares e artistas independentes, visto que não estava presente nos currículos escolares. Em 1971, com a Lei de Diretrizes e Bases, a arte passou a ser componente curricular obrigatório e, mediante a demanda do mercado, foram criados cursos superiores de licenciatura em educação artística. Em seu artigo Reflexões sobre a formação profissional do artista da dança (2003), Marcia Strazzacappa argumenta que não foi a legislação que impulsionou a criação de cursos, mas sim um movimento advindo dos próprios profissionais da área, que por não terem uma instituição à qual confiarem sua formação (durante mais de vinte e cinco anos existia apenas uma faculdade de dança no Brasil, na Universidade Federal da Bahia), começaram a cursar outras faculdades, aliando e procurando aportes para a pesquisa em dança. Com isso, a autora conclui que o que impulsionou de fato o surgimento dos primeiros cursos de graduação em dança foi a pesquisa.

Os espaços criados pela confluência entre dança e educação possibilitam enxergar inúmeras situações significativas em que podemos dizer que a educação vai muito além do universo do ensino. Em um contexto no qual entende-se que a educação tem eminentemente uma função social e política, podemos deduzir que a dança auxilia no desenvolvimento do pensamento crítico, da consciência ética e a impregnação de sentido sobre os atores e atos que compõem nossas vidas cotidianas. Refletindo, portanto, sobre o desenvolvimento de indivíduos conscientes e atuantes na sociedade, o binômio dança-educação nos leva a pensar sobre os possíveis locais 
Conceição | Conception

Revista do Programa de Pós-Graduação em Artes da

Cena, Universidade Estadual de Campinas

Performing Arts Graduate Program Journal, University of

Campinas

de ensino da dança e possíveis percursos de formação dos artistas da dança. No texto Onde se produz o artista da dança? (TERRA, 2009, p 67), os três caminhos 5 apontados como possíveis são:

- Cursos Técnicos (antigo $2^{\circ}$ Grau);

- $\quad$ Cursos de Graduação em Dança (antigo $3^{\circ}$ Grau);

- Cursos Livres ou de Formação não reconhecidos pelo MEC (ensino não formal).

No presente texto buscamos, através de cinco tópicos, propor reflexões que evidenciam a importância e as possíveis contribuições do licenciado em dança no ambiente de ensino não formal. Com enfoque nas academias e companhias de dança, mostramos algumas possibilidades de atuação destes profissionais, levando em consideração a formação universitária como direcionadora da metodologia, conteúdos, prioridades e filosofia de ensino.

O tópico 1 expõe questões sobre a metodologia em dança e a formação do profissional/professor que atuará na área de ensino não formal. Conceber uma identidade metodológica, superar as dificuldades de mercado e proporcionar um ensino-aprendizagem de qualidade que assegure um desenvolvimento transformador do aluno, com o caráter crítico reflexivo, são algumas das reflexões dispostas no texto.

Elucidando os contextos que envolvem a atuação do licenciado no ambiente não formal, o tópico 2 buscará apresentar propostas de exercícios na aula de dança contemporânea para serem aplicadas em estúdios e academias de dança visando à

\footnotetext{
5 A educação formal pode ser compreendida como aquela que está presente no ensino escolar institucionalizado, cronologicamente gradual e hierarquicamente estruturado, e a informal como aquela na qual qualquer pessoa adquire e acumula conhecimentos, por meio de experiência diária em casa, no trabalho e no lazer. A educação não formal, porém, define-se como qualquer tentativa educacional organizada e sistemática que, normalmente, se realiza fora dos quadros do sistema formal de ensino.

BIANCONI, M. Lucia; CARUSO, Francisco. Educação não-formal. Ciência e Cultura, v. 57, n. 4, p. 2020, 2005.
} 
Conceição | Conception

Revista do Programa de Pós-Graduação em Artes da

Cena, Universidade Estadual de Campinas

Performing Arts Graduate Program Journal, University of

Campinas

inserção do profissional licenciado pela universidade no "tradicional" ensino não formal de academias no Brasil, procurando conciliar e articular as divergentes linhas metodológicas a respeito da formação em dança entre as duas instituições (a formal e a não formal).

Por fim, o tópico 3 traz um recorte sobre duas companhias de dança formadas por bailarinos advindos do ensino não formal. Dentro desses ambientes, são analisados e discutidos os enfoques de cada uma no que diz respeito aos processos de criação e composição, levantando questões sobre eficácia e potencialidade da transmissão de conhecimentos e expressão de cada um.

\section{O ensino de dança nos estúdios/academias e a formação de uma identidade metodológica do docente de dança}

Em se tratando do ensino de dança, temos vários aspectos a serem explanados. O contexto do ensino, do professor e do aluno. O contexto não formal é onde se encontram as academias e estúdios de dança, locais onde não se tem uma formação de artistas através de uma grade curricular universitária e o intuito primeiro não é formar profissionais de dança.

Entre os professores/profissionais de dança que atuam nesses locais, poucos têm uma formação acadêmica, e sua grande maioria vem de um ambiente artístico e de um mercado de trabalho que não tem vínculo com prefeituras, estados, ou o próprio Ministério da Educação e Cultura.

Os alunos têm um perfil bem variado, diferente devido à faixa etária e o motivo porque procuram aulas de dança. Muitos alunos vêm com a ideia de "modelar" o corpo, outros por saúde, alguns por hobby. O conceito de que a dança é arte e que pode promover um processo de transformação nos alunos, conduzindo a uma reflexão sobre o próprio corpo e o ambiente social, raramente é o principal 
Conceição | Conception

Revista do Programa de Pós-Graduação em Artes da

Cena, Universidade Estadual de Campinas

Performing Arts Graduate Program Journal, University of

Campinas

motivo que leva os alunos a praticarem a dança e a experimentarem as aulas dentro deste contexto de academias e estúdios de dança.

Quais são os desafios que o professor vai enfrentar neste local? O que um professor licenciado em dança pode fazer para apresentar um diferencial?

A formação do professor licenciado, que muitas vezes veio do meio das academias de dança, proporciona um conhecimento universitário, sendo que, após cursar a universidade, ele por vezes enfrenta os dilemas das contradições entre as diferentes visões de dança de cada um desses ambientes, além do desafio naturalmente apresentado pelo mercado de trabalho.

Durante todo este processo de formação é importantíssima a questão da identidade do docente, que visa à diferenciação do que é dele, em relação a outros professores e seus métodos. Seu modo de ser no contexto do ensino de dança e seu comportamento em sala, como transpõe seu conteúdo, seus valores e princípios, definem o que poderíamos chamar de sua identidade metodológica.

No momento em que, após a saída da universidade, a formação da identidade deste novo professor está ainda bastante latente, os conteúdos aprendidos no ambiente acadêmico levam, em geral, o licenciado a se mostrar um profissional com muita informação e pouca prática e aplicação dessas informações. O licenciado percebe que adquiriu vários princípios e conceitos, mas não tem claro, muitas das vezes, para ele mesmo, qual será seu modus operandi daquele momento em diante. Por isso é crucial sua entrada no mercado de trabalho; a consolidação de grande parte de sua identidade, que é mutável, acontecerá na prática da dança e de seu ensino. E quando esse professor for capaz de unir o conhecimento acadêmico com o trabalho empírico, tornar-se-á um professor global.

Com a entrada desse licenciado no ambiente das academias e estúdios de dança, ele ainda está em processo de se tornar um professor completo e apto a desenvolver um bom trabalho pedagógico e didático. Contudo, os ambientes dos estúdios e academias de dança oferecem uma demanda que não se encaixa, na primeira impressão, com o professor/licenciado em termos de conteúdos de dança a 
Conceição | Conception

Revista do Programa de Pós-Graduação em Artes da

Cena, Universidade Estadual de Campinas

Performing Arts Graduate Program Journal, University of

Campinas

serem ministrados. Para os alunos das academias de dança, muitas das vezes o ideal estético de dança almejado não condiz com o que o professor disponibiliza em seu trabalho. Nas academias de dança podemos dizer, assim como Fortin, que: “O ensino da dança permanece arraigado em grande parte aos usos e costumes da tradição e que, segundo ela, é o recurso mais frágil para se delimitar uma ação pedagógica"(FORTIN, 2003).

As demandas do mercado colocam esse perfil de professor licenciado diante de um primeiro desafio. Que conteúdos ministrar e de que maneira? Como conciliar aquilo em que acredita/almeja com o que lhe é postulado, para que se tenha o melhor para todos no processo de ensino aprendizagem?

O conteúdo surgirá a partir da escolha do modo como transpor esse conteúdo. Então, o método seria um modo focado e específico de transposição de um conteúdo. Um exemplo seria o método de Rolf Gelewski 6 . O método compreende vários tópicos, tais como Técnica Corporal (exercícios técnicos criados a partir de percepções das possibilidades de movimento do próprio corpo de Gelewski), Estudos Básicos de Formas (exercícios com qualidades antagônicas da forma dos movimentos, tais como: simétrico e assimétrico, curvo e reto, contraído e dilatado), Rítmica Métrica (exercícios de tempo e ritmo com base em metros gregos), Estudo do Espaço (aspectos da localização no espaço, tais como dimensões, direções e caminhos no/do espaço), Métodos de Improvisação (podendo ser improvisações estruturadas ou livres), Composição e Coreografia (exercícios voltados para a apresentação de dança em público, sendo o uso do termo coreografia aplicado a trabalhos em grupo e do termo composição a solos) e, por fim, a Filosofia da Dança

\footnotetext{
6 "Rolf Gelewski nasceu em Berlim em 1930. Na juventude ocupou-se com música, pintura e poesia, até encontrar a dança. Decidiu-se pela última como caminho de vida e de crescimento, estudando dança criativa com Mary Wigman e Marianne Volgelsang. Entre 1953 e 1960 foi dançarino solista e professor no Teatro Metropolitano de Berlim. Em 1960, Gelewski foi chamado ao Brasil pela Universidade Federal da Bahia, onde lecionou até 1975 no Curso de Graduação em Dança. Ocupou os cargos de Diretor da Escola de Dança, Dirigente e Coreógrafo do Grupo de Dança Contemporânea e Chefe do Departamento de Integração e Educação Artística" (PASSOS, 2013, p. 72).
} 
Conceição | Conception

Revista do Programa de Pós-Graduação em Artes da

Cena, Universidade Estadual de Campinas

Performing Arts Graduate Program Journal, University of

Campinas

(uso de textos e materiais que levam ao desenvolvimento do pensamento e da reflexão).

Todos esses tópicos formam o método de Rolf Gelewski, um modo de transpor conteúdos e de ministrar aulas com música e dança. Um método que pode ser apropriado por vários professores e ser utilizado unicamente, ou em conjunto, com outros instrumentos (métodos) para ministrar aulas, ciente de que mesmo com essa junção de abordagens, a identidade metodológica do professor pode continuar sendo singular. Ele pode se utilizar do método, sem mudá-lo, ou pode criar sua própria metodologia a partir dele.

Sendo assim, se o local em que o professor atuar tem a expectativa de que as aulas de dança tenham um conteúdo técnico específico, as aulas serão trabalhadas a partir de um método. Se não for um local "tradicional" que busca essa abordagem, não tendo uma especificidade, o professor licenciado trabalhará a partir da utilização de uma metodologia própria, com sua identidade metodológica, cuja forma de ministrar aulas pode englobar todos os outros métodos e mais o seu próprio. Trabalhando a partir de sua identidade metodológica fica mais simples resolver o dilema de como ministrar o que a academia de dança acredita ser necessário e o que o professor entende e crê ser o cerne da dança e da arte que transcende a técnica, levando a um processo de ensino-aprendizagem que promove a reflexão e o crescimento mútuo de todos os incluídos neste processo.

O ponto de encontro, que dá a liberdade metodológica, permite que o licenciado em dança se destaque neste ambiente, pois consegue unir interesses, informações e conhecimento. Ele se torna o professor agente que é descrito abaixo:

Suas colaborações educacionais críticas, este agir educacional reflexivo coloca, num mesmo patamar, o agir político, porque é através da análise da situação presente e concreta da realidade escolar que poderemos organizar nossas práxis enquanto professores transformadores (MAÇANEIRO, 2010). 
Conceição | Conception

Revista do Programa de Pós-Graduação em Artes da

Cena, Universidade Estadual de Campinas

Performing Arts Graduate Program Journal, University of

Campinas

Para que ocorra um ensino e uma aprendizagem de qualidade, devemos relacionar as questões reflexivas/críticas que trazem o viés do sensível do ser humano com a parte técnica pedagógica (técnica a qual reúne todo o estudo de transposição didática, avaliação, pedagogias aplicadas, métodos e metodologias), conjuntamente com a parte prática/real que traz a racionalidade e a práxis em si do ensino-aprendizagem, principalmente em se tratando de dança.

Um professor licenciado que tem a capacidade de arcar com esses aspectos é um professor reflexivo, que gera condições de um ambiente propício à assimilação de informações e transposição de conhecimento. Assim, os objetivos a serem alcançados constituem um ponto muito importante, pois quando se tem objetivos semelhantes, como deve ser, no caso da academia e do professor atuante, torna-se mais possível que se concretizem as metas.

Como os objetivos e metodologias são abertos e não dependem de nenhuma legislação, nesses ambientes de academias e estúdios de dança poderíamos dizer que em diferentes academias existem alguns objetivos em comum, como: o bem-estar do aluno, a satisfação deste e o desenvolvimento de uma arte que contemple criações consideradas "belas" em uma concepção mais geral comumente encontrada na sociedade. Há no interior desses ambientes a possibilidade de trabalhar com agrupamentos de objetivos, metas e ideias, viabilizando a todos os envolvidos neste contexto um ganho na práxis.

O licenciado em dança, com todo esses saberes acumulados e empregados, tendo objetivos especificados e identidade esclarecida, consegue trazer uma dimensão sensível para o aluno e um estado de corpo/atenção que só se consegue com a dança.

A dança pode ajudar o ser humano a se transformar e se tornar mais completo com a prática do movimento em sua vida. Um ser holístico, que tem a sua visão de mundo e se conduz na sociedade mais ativamente, buscando mudanças melhores para o planeta através do próprio corpo, que possuirá o domínio do corpo através das diferentes técnicas de dança existentes e dos diversos modos de 
Conceição | Conception

Revista do Programa de Pós-Graduação em Artes da

Cena, Universidade Estadual de Campinas

Performing Arts Graduate Program Journal, University of

Campinas

transposição. Independentemente do como, ou qual conteúdo a ser aprendido, sempre existirá o cuidado com o aluno, para a promoção de sua autonomia e emancipação na sociedade de uma forma geral.

Para tanto, é preciso criar a conexão entre meios e resultados, por meio de resoluções criativas que o licenciado desenvolveu em sua graduação de dança. A prática consciente acontece devido à capacitação que o professor adquiriu e que ajuda os alunos a dançarem sua próprias descobertas.

\section{Uma proposta de exercícios para aulas de dança contemporânea em estúdios e academias}

A dança contemporânea é de difícil conceituação. Partindo do desejo de libertação, desconstrução e ruptura com as técnicas clássicas e modernas e suas concepções rígidas, é composta por variadas formas de pesquisa, fazendo com que a diversidade seja uma de suas grandes marcas. A formação de seus artistas bailarinos geralmente reúne diversas experiências corporais, abarcando uma variedade de tendências e formas, que serão escolhidas para melhor conquistar um determinado fim. A partir de "redes de influências e contágios múltiplos" (SIQUEIRA, 2006, p. 107) o artista cria e vive a dança nos tempos contemporâneos. Portanto, dança contemporânea se define muito mais pela perspectiva com a qual se enxerga a dança nos dias atuais do que por uma técnica codificada específica. De acordo com a pesquisadora Cássia Navas, a dança contemporânea pode ser vista como um "guarda-chuva", abrigando vários estilos e técnicas diferentes, na busca por trabalhar questões do sujeito contemporâneo. Corpo e dança, ambos reflexos de seu tempo/fluxo/ritmos: instantâneos, plásticos, fragmentados, virtuais, multiculturais.

Ao mesmo tempo em que a dança contemporânea acompanha as transformações do mundo, consistindo numa manifestação deste, ela também se coloca como resistência de valores ao reafirmar a face subjetiva, sensível e poética do 
Conceição | Conception

Revista do Programa de Pós-Graduação em Artes da

Cena, Universidade Estadual de Campinas

Performing Arts Graduate Program Journal, University of

Campinas

ser corpo-mente, aspecto cada vez mais obliterado frente ao desenvolvimento tecnológico e intelectual da sociedade.

[...] a dança contemporânea feita nos dias de hoje caracteriza-se por uma destituição de fronteiras no que tange às técnicas corporais, vincula-se a uma integração das várias linguagens artísticas e tem a investigação do movimento como o mote para a criação. (RODRIGUES, 2010, p. 1444).

Este trabalho apresenta reflexões que buscam nortear a construção de propostas para a inserção do profissional licenciado em dança pelas universidades em ambientes de ensino não formal, como as academias e estúdios de dança, no contexto da dança contemporânea, campo em que me insiro no atual momento de minha vida profissional. Partindo da problemática da divergência existente entre o trabalho de concepção e formação em dança realizado por esses dois ambientes (universidade e academias e estúdios de dança no Brasil), este texto busca debater as questões e circunstâncias dessa divergência e propor uma metodologia continuada que concilie as características de trabalho de cada instituição de formação, sem que uma precisa anular a outra, para possibilitar que o profissional licenciado possa se adaptar e somar no ensino não formal realizado nas academias e estúdios de dança no Brasil, possivelmente ajudando a transformá-lo.

Pois então, quem é o licenciado em dança pelas universidades? Quais são as qualificações que o diferenciam? Em “A dança depois da Universidade: e agora?" (ROCHA, 2009), a autora aponta que o aluno licenciado, em sua (trans)formação como professor de dança é estimulado a afinar percepções, criticar e aprender. Ao passar por um processo de singularização, tomando a si mesmo como estudo de caso, o aluno é encaminhado e orientado a embrenhar-se no autoconhecimento e reconhecimento de seu corpo, seus movimentos e seu ser.

Aulas de anatomia, educação somática, técnicas codificadas, ateliês de criação, expressão corporal, produção cênica, história da dança e da arte e iniciação à 
Conceição | Conception

Revista do Programa de Pós-Graduação em Artes da

Cena, Universidade Estadual de Campinas

Performing Arts Graduate Program Journal, University of

Campinas

pesquisa compõem um currículo que busca formar artistas da dança na atualidade, com conhecimentos da prática artística e teórico-científicos. Rocha explica que a universidade busca, enfim, habilitar o aluno a ser um agente capaz de inventar, contemporâneo de seu tempo, seu lugar: "Não a inserir-se no mundo, a pertencer a ele, mas a inventar o mundo" (ROCHA, 2009, p. 96). Uma vez em que nos tempos atuais vivenciamos uma enorme crise no mercado de trabalho, os artistas licenciados não têm perfil para preencher vagas, mas sim, para criar "condições de possibilidades que inventarei para existir e permanecer (resistir). Teremos que inventar a própria necessidade de nossa existência e de nossa permanência" (ROCHA, 2009, p. 102).

Mas a história da licenciatura em dança no Brasil ainda pode ser considerada recente. Onde se sustenta, portanto, a tradicional e mais popular formação em dança? Qual é o ensino não formal tradicional das academias de dança no Brasil? No artigo "Reflexão sobre a formação profissional do artista da dança", Strazzacappa (2003) esclarece que a formação do artista da dança acontece antes mesmo de chegar às universidades. É dada, segundo a autora, em sua maioria, através de academias, cursos livres, oficinas culturais, estúdios, entre outros. Nesse ambiente, a metodologia predominante é a tradição oral: existe o mestre que fala e demonstra, e o aluno que reproduz o gesto, perpetuando este modo de ensino em que há sempre um modelo a ser seguido e obedecido, e esses alunos serão os futuros mestres que vão ensinar assim como foram ensinados. O ensino vai se especificando de acordo com o fim desejado (ex.: lazer, espetáculo, saúde, etnia, expressão); seja qual face for, o ensino da dança "é construído na relação entre três elementos: conhecimentoeducador-educando. A qualidade da formação dependerá de como se dá essa relação básica" (STRAZZACAPPA, 2003, p. 191).

Os desafios que o licenciado pode encontrar no ambiente de academia e estúdios de dança são muitos. Em minha própria caminhada na dança, habitei e ainda habito esses dois universos, como estudante em formação. Estar do outro lado da ponte "professor-aluno", vivenciando a perspectiva do educador, é despertar 
Conceição | Conception

Revista do Programa de Pós-Graduação em Artes da

Cena, Universidade Estadual de Campinas

Performing Arts Graduate Program Journal, University of

Campinas

para outras responsabilidades, expectativas e inseguranças. Dentre essas, questões que abordam a didática (o que ensinar, como, por quê) e a melhor metodologia de ensino, perfil de cada turma, dificuldades e estratégias para superá-las são questões sobre as quais hoje me debruço.

Minhas experiências como professora de dança contemporânea em ambientes não formais (refiro-me aqui à academias e estúdios de dança) são ainda poucas e frágeis. O primeiro desafio foi propor um trabalho diferente do modus operandi das academias, não apenas quanto à metodologia das aulas, mas também quanto a seus propósitos e valores. Pelo fato de os alunos estarem condicionados a um sistema de ensino que valoriza a técnica, a repetição e reprodução de movimentos ditados por uma figura de poder (a mestra/o mestre), eles atrofiam suas potencialidades e desempenhos no campo sensível, expressivo e proprioceptivo. São componentes passíveis do processo de ensino-aprendizagem; estão acostumados a receber o conhecimento, não protagonizando seus próprios processos. A noção de corpo é tão distanciada do ser que, ao se passar exercícios usando apenas a fala, os alunos em geral sentem dificuldades em compreender nomes e partes do corpo. Outro grande desafio, conectado ao primeiro, é o objetivo da procura pela dança: generalizando, pude observar que grande parte das pessoas que procuram uma academia de dança o fazem por diversos interesses como: a) hobby: procuram entretenimento, divertirse, relaxar, "dançar no espetáculo do final do ano"; b) por tradição: mães colocam suas filhas em aulas de dança movidas pelo estereótipo social do gênero feminino ("é coisa de menina”); c) opção de exercício físico; e por último, e menos comum: d) aprender e desenvolver-se em uma área do saber artístico. Dessa forma, a academia se adequa ao esquema de oferta e procura e as aulas, com exceção ao ballet clássico, que possui uma esquematização e metodologias muito claras e tradicionais, possuem uma preocupação maior em satisfazer esses interesses predominantes e em reproduzir formas, estéticas e modismos, do que com a formação de artistas da dança, corpos e mentes flexíveis, criativos e poéticos. 
Conceição | Conception

Revista do Programa de Pós-Graduação em Artes da

Cena, Universidade Estadual de Campinas

Performing Arts Graduate Program Journal, University of

Campinas

Acredito que o licenciado em dança possa contribuir para a própria permanência da dança na condição de área de conhecimento, bem como para seu ensino, sendo agente ativo em sua transformação, ampliação, superação e qualificação dentro do mais abrangente e tradicional sistema de prática e disseminação da dança no país: as academias e estúdios de dança. Para tal, deve haver muito trabalho e tempo, para que, camada por camada, a dança que se desenvolve nas universidades e centros de pesquisa possa conquistar os demais ambientes e segmentos onde se pratica, se produz e se pensa a dança no país.

À luz das reflexões levantadas acima, o maior desafio com o qual me deparei foi exatamente como construir um modelo de aula que não seja radicalmente diferente do ambiente de ensino das academias de dança, mas que trouxesse estímulos e provocações que iriam preparar e fertilizar um terreno para o desenvolvimento de um trabalho mais sensível, expressivo, poético e crítico.

A seguir apresento oito propostas de exercícios para uma aula de dança contemporânea dentro de academias e estúdios de dança. Tais propostas se baseiam na confluência das diversas técnicas, trabalhos e conteúdos aos quais fui apresentada e que absorvi durante minha formação, assim como no contínuo aprendizado que o estar em sala de aula proporciona. Resultam, portanto, de uma formação bastante híbrida dentro das técnicas de dança contemporânea, técnica clássica, moderna e educação somática. Tratarei dos exercícios com exemplos amplos, que possam ser adaptados e reajustados de acordo com as diferentes faixas etárias e contextos.

Exemplo I: comecemos pelo diálogo, estabelecendo um ambiente e uma relação amigável à comunicação e à troca de informações, pois trabalhar com o corpo no começo das aulas sempre representa uma continuação: desde os primórdios da experiência motora do aluno, que se propõe ao estudo de uma nova linguagem corporal, ele já carrega consigo uma diversidade de informações psicomotoras, por não se tratar de uma página em branco, pronta para ser preenchida. Annie Suquet, em seu artigo “O corpo dançante: um laboratório da percepção" (2008), discorre 
Conceição | Conception

Revista do Programa de Pós-Graduação em Artes da

Cena, Universidade Estadual de Campinas

Performing Arts Graduate Program Journal, University of

Campinas

sobre como Rudolf Laban aborda a corporeidade do homem moderno como um palimpsesto, por exemplo. O pesquisador acreditava que toda a evolução da matéria estaria nela codificada, acessível sob a forma de traços e de vibrações, segundo a autora. Acredito que começar um trabalho com uma turma exija um diálogo, uma apresentação, na qual eu como professora possa adquirir um conhecimento prévio a respeito da trajetória de cada aluno, suas referências e expectativas a respeito da dança contemporânea.

As contribuições dos alunos, não somente emergidas na fala, são informações que norteiam o caminho do professor, na busca por sensibilizá-los melhor e de forma mais abrangente, unindo, assim, a tomada de consciência corporal com uma postura criativa e analítica. O diálogo deverá ser incitado e estimulado em todo o decorrer do trabalho, fazendo parte do processo de aprendizagem da dança.

Exemplo II: todos deitados no chão, olhos fechados com atenção na respiração para acordar os sentidos proprioceptivos e estabelecer um estado de presença ativo. Utilizando o recurso de imagens, nesse momento pode-se propor aos alunos "novos olhares" para o corpo: revisitar e reconhecer, mentalizando cada parte de si e de suas relações com o chão que as sustenta. Partindo de uma perspectiva somática, esse momento busca iniciar uma exploração proprioceptiva que subsidiará todo o trabalho que seguir. Recursos didáticos: fala, figuras de linguagem.

Exemplo III: deitados, os alunos são orientados a começar a reconhecer os espaços articulares e a movimentá-los, com o auxílio do chão, num espreguiçar-se, soltando tensões e criando flexibilidade. Ainda com os olhos fechados, os alunos são estimulados a interpretarem as propostas feitas pelo professor, a respeito do despertar das articulações, a partir das percepções de seus corpos, evitando o juízo de valor entre certo e errado. Após esse momento introspectivo, os olhos se conectam com o exterior e começam também a trabalhar o foco, trazendo a presença de cada um para o espaço e o momento presente. E então os alunos passam a utilizar-se cada vez de menos apoios e a se distanciar do chão, passando pelos níveis médio e alto, podendo também se deslocar. É hora de utilizar o movimento total do 
Conceição | Conception

Revista do Programa de Pós-Graduação em Artes da

Cena, Universidade Estadual de Campinas

Performing Arts Graduate Program Journal, University of

Campinas

corpo, explorando níveis e deslocamentos, realizando a exploração em tempos cada vez mais rápidos. No estágio mais veloz, com o corpo e a atenção ativos, em cada nível pode-se propor ao aluno que haja uma micropausa para uma foto, captando uma determinada posição do corpo, buscando a cada nova transição um diferente tipo de apoio no chão.

Terminamos esse momento, por fim, de volta ao chão, em repouso. Através do estudo das partes do corpo, podemos explorar em uma improvisação guiada suas possibilidades de movimentação e as relações que estabelecem com o espaço e o chão, ora cedendo, ora empurrando. É explorada também a relação que se estabelece entre velocidade e qualidade de movimento, como, por exemplo: lento e fluido, rápido e seco. Recursos didáticos: Fala, música.

Exemplo IV: Com a informação do cansaço e do corpo aquecido/acordado, os alunos levam novamente a atenção ao corpo e são encorajados a relaxarem ainda mais seu peso no chão, reconhecendo-se a partir da relação com ele. Acrescenta-se a atenção à respiração e, no ritmo ditado por ela, os alunos começam a expandir o corpo, vetorizando todas as extremidades para longe do seu centro durante as inspirações e contraindo o corpo, trazendo suas extremidades para próximo do centro, durante as expirações. Ainda, somente usando o recurso da fala, e sem a referência do espelho, o professor guia os alunos a expandirem e contraírem o corpo conectado com sua respiração, entretanto agora a contração será realizada levando o corpo para uma das laterais numa posição fetal, retornando, durante a inspiração, à posição expandida de costas ao chão e repetindo a contração para a outra lateral. Depois dessa primeira exploração individual, o professor senta-se à frente da turma e ensina uma sequência de movimentos a ser repetida por eles, que vão explorar variações desse princípio de expansão/contração e centro/extremidade. Recursos didáticos: fala, música, demonstração.

Exemplo V: na posição em que terminamos o último exercício, o professor, situado à frente da turma, inicia com os alunos alguns alongamentos. Enquanto os alunos alongam, o professor pode caminhar entre os alunos e auxiliá-los, quando 
Conceição | Conception

Revista do Programa de Pós-Graduação em Artes da

Cena, Universidade Estadual de Campinas

Performing Arts Graduate Program Journal, University of

Campinas

necessário, com o toque. Terminamos esse momento sentados no nível médio, frente ao espelho. Recursos didáticos: fala, música, demonstração, toque.

Exemplo VI: com uma determinada sequência no nível médio, trabalhamos com deslocamentos espaciais. Com o recurso da fala, do espelho, da música, e agora de uma contagem e ritmo, a sequência (e seus conteúdos) é praticada. Começamos a estimular os alunos a investirem em suas individualidades, a preencherem $\mathrm{o}$ movimento com intenção e presença e com a noção de que "erros" são apenas outros percursos que podem/devem ser explorados. Recursos didáticos: fala, música, demonstração, espelho, contagem.

Exemplo VII: Na posição em que finalizamos o último exercício, o professor guia os alunos numa exploração de apoios no nível médio: o professor dirá quantos apoios eles devem ter no chão. Por exemplo: o professor pede 5 apoios, e os alunos poderão escolher quais partes do corpo estarão em contato com o chão, como mão, orelha e cotovelo direito, pé e joelho esquerdo. Depois que essa exploração aconteceu num espaço fixo, expandimos para deslocamentos, aumentando a dificuldade. O exercício pode também se desenrolar numa brincadeira de pega-pega, tornando o momento da exploração mais lúdico. Recursos didáticos: fala, música, jogo.

Exemplo VIII: Proposta de uma frase coreográfica no nível alto. Diretamente conectados com a música, nesse momento da aula os alunos, após apreenderem a frase, são fortemente estimulados a se apropriarem da dança e a encontrarem expressividade para aqueles movimentos. A proposta é trabalhar de forma ampla a absorção dos conteúdos trabalhados anteriormente na aula, a memorização e absorção dos movimentos, ritmo e expressividade, introduzindo a prática cênica. Tal frase coreográfica pode subsidiar um estudo coreográfico individual de cada aluno na proposta de ressignificar os movimentos, trabalhar outras qualidades, intenções, tempos e velocidades, transformando-a. Recursos didáticos: fala, música, demonstração, espelho, contagem. 
Conceição | Conception

Revista do Programa de Pós-Graduação em Artes da

Cena, Universidade Estadual de Campinas

Performing Arts Graduate Program Journal, University of

Campinas

O recurso metodológico de trabalhar com sequências pré-determinadas é o modo mais utilizado dentro de academias e estúdios de dança, e muitas vezes a repetição de passos se afirma como melhor método. Por se tratar de uma característica tão enraizada no ambiente não formal, em minhas propostas escolhi por englobá-las e ampliar o potencial que esse recurso pode ter numa construção técnica e artística do aluno, levando-o a apropriar-se das propostas e transcendê-las, subsidiando assim um trabalho criativo, bem como permitindo ao professor observar o que o aluno compreendeu e a fazer as correções necessárias. Quanto ao espelho, em muitos momentos ele distancia o aluno de si mesmo, em outros serve como um grande auxiliar do professor, principalmente se for o caso de uma turma grande. Escolhi, nessas propostas, utilizar esse recurso de acordo com necessidades objetivas.

Nas propostas, procurei aliar momentos de explorações e experimentações à técnica, construir momentos e brechas, para ir aos poucos introduzindo a pesquisa e despertando a criatividade e improvisação dentro de uma aula técnica, entendendo esses elementos como outras faces dessa abordagem. Comecei a arredondar as tais aulas quadradas.

Em todas as propostas apresentadas, existe um último detalhe que deve embasar toda a prática docente: a escuta. Acredito que deve haver uma abertura para a improvisação, para o inesperado, dentro de todo plano de aula preparado, pois de cada aluno despontam diversas outras formas de percorrer o mesmo caminho, com diversas bagagens e memórias corporais, sendo eles seres pensantes e criadores e considerando que, no momento em que acontece a aula, a atenção para a relação que está sendo construída com a turma e a percepção do andamento da proposta é mais importante do que estar cegamente focado na estrutura de aula planejada anteriormente para a turma idealizada. Para tanto teria de haver antes a clareza em relação à didática (o que ensinar, como), à proposta do dia (quais conteúdos escolhidos para serem abordados), à visão de corpo, da dança e da 
Conceição | Conception

Revista do Programa de Pós-Graduação em Artes da

Cena, Universidade Estadual de Campinas

Performing Arts Graduate Program Journal, University of

Campinas

educação, para que a estrutura da aula possa ter mais liberdade e flexibilidade de se ajustar ao momento e à turma, fazendo dos alunos co-criadores de todo o processo.

\section{Potencialidades do ensino aprendizagem em processos criativos de companhias de dança}

Os espaços criados pela confluência entre dança e educação possibilitam visualizar inúmeras situações significativas em que podemos dizer que a educação vai muito além do universo do ensino-aprendizagem. Nas palavras de Strazzacapa, "toda dança promove transformação, logo, toda dança é educação" (2009, p. 44).

Refletindo sobre um panorama mais amplo, vemos que as condições sociais e políticas para o desenvolvimento da dança-educação muitas vezes não estão afinadas com processos de transformação do indivíduo. Em um contexto marcado pela reprodutibilidade e pela eficiência na produção de algo, a valorização exacerbada do desempenho, da performance e da realização acaba por atrofiar o caráter educacional da dança, limitando-a, muitas vezes, a uma função de promover condicionamento físico. Muitas vezes, os conhecimentos são recebidos passivamente e reproduzidos a fim de alcançar determinados produtos, com um certo descompromisso com a formação artística e humana dos alunos. Contraditoriamente ao que se acredita ser produtivo e gerador de evoluções e oportunidades em um sentido de transformação mais integrado, essa situação acaba por eliminar as possibilidades de diálogo com o mundo pulsante e social do trabalho, que exige grande capacidade de comunicação entre as pessoas, pensamentos e possibilidades de entendimento.

Apesar disso, no campo das artes, sabemos há tempos que a dança se faz essencial na ampliação da compreensão dos múltiplos sentidos através dos quais a realidade pode ser vista, interpretada e vivida. Inclusive, na última década, como observado por Costas (2009) no artigo “Onde se produz o artista da dança?”, os inúmeros acontecimentos de caráter artístico, cultural, sociopolítico e econômico 
Conceição | Conception

Revista do Programa de Pós-Graduação em Artes da

Cena, Universidade Estadual de Campinas

Performing Arts Graduate Program Journal, University of

Campinas

desenharam e reformularam os artistas da dança, o mercado de trabalho, as áreas de atuação e, consequentemente, as demandas de formação da área. Quando pensamos na multiplicidade de possibilidades de atuação dos artistas da dança, surge também o questionamento sobre o que acontece em seus locais de formação. Nesse sentido, este texto se propõe a discutir sobre o papel dos espaços de ensino da dança não formais e também que tipo de profissionais eles formam.

Atualmente, grande parte das pessoas que atuam profissionalmente com a dança vieram de academias de dança, escolas ou estúdios não reconhecidos pelo Ministério da Educação (MEC), ou seja, instituições de ensino não formais. Esses ambientes apresentam, geralmente, uma certa indefinição em relação aos objetivos de ensino e formação, devido, principalmente, ao fator rentável e financeiro que é essencial para a manutenção desses espaços. Parece-me que a preocupação com a imagem do lugar e dos bailarinos, com a forma como se vendem suas aulas e apresentações, com o número de alunos, com a competitividade em relação a outras academias da mesma região, entre outras coisas, acabam sendo as principais questões, em detrimento do conteúdo e da qualidade da formação dos alunos.

Partindo de experiências pessoais, posso afirmar que esses profissionais criados unicamente dentro desses ambientes saem com um grande potencial técnico e, geralmente, seguem um padrão estético que obedece às necessidades midiáticas do mundo em que vivemos. E, se por um lado o treinamento é muito bem construído no que se refere à reprodução precisa de movimentos, por outro lado, é possível observar um grande déficit na formação sensível e expressiva do bailarino.

A partir desta realidade, a dança se configura como um importante paradoxo a ser vislumbrado. Este me instigou a levantar algumas questões que me levaram às próximas reflexões apresentadas: como articular os focos técnico e sensível no ensino da dança nesses contextos? Como essa articulação forma profissionais mais bem preparados para atuar no mercado de trabalho atual? Como os conhecimentos adquiridos no meio acadêmico podem ser aplicados no contexto das academias tradicionais de dança? E, finalmente, como um licenciado em dança 
Conceição | Conception

Revista do Programa de Pós-Graduação em Artes da

Cena, Universidade Estadual de Campinas

Performing Arts Graduate Program Journal, University of

Campinas

pode atuar na formação de bailarinos, levando em conta seus conteúdos e entendimentos sobre corpo, dança e ensino apreendidos durante a graduação?

Para discutir as questões mencionadas acima, apresento aqui um recorte que traz a realidade vivida em duas companhias com as quais tive contato durante meu período de formação na universidade. A escolha desse recorte foi feita inicialmente pela oportunidade que tive de assistir às suas produções, que refletem diretamente o foco de seus estudos e, portanto, evidenciam as vantagens e desvantagens de seus métodos de trabalho. Foi a partir deste ponto que surgiu o interesse em analisar como uma formação integrada entre formação técnica e exploração do sensível pode produzir uma arte íntegra e plena de sentidos.

\section{Jazz dance e sapateado como pontos de partida}

De um lado, uma companhia de Jazz Dance sediada em São Paulo, e do outro, uma companhia de Tap Dance (sapateado americano) de Nova Iorque, nos Estados Unidos. Ambas as companhias trabalham com bailarinos formados em dança por instituições de ensino não formais e se diferenciam entre si pela abordagem técnica e criativa com as quais trabalham.

É preciso aqui, juntamente com a apresentação das companhias, frisar que o modo como trabalham é um reflexo direto das construções históricas que constituem as danças focadas em cada caso: tanto o jazz, quanto o sapateado, são entendidos como formas vernaculares de dança dos Estados Unidos e ambas têm fortes influências do jazz music e do blues, que nasceram das manifestações culturais da comunidade negra escravizada durante o século XVIII. Tendo como base o improviso e o autoaprendizado, elas possuem em suas raízes um caráter comum de entretenimento. As duas formas de expressão se popularizaram com o passar do tempo, ocupando o riquíssimo cenário cultural de Nova Orleans em meados do século XIX, subindo aos palcos dos teatros de Vaudeville e chegando posteriormente às luzes de Hollywood e aos grandes shows da Broadway. No entanto, com o passar 
Conceição | Conception

Revista do Programa de Pós-Graduação em Artes da

Cena, Universidade Estadual de Campinas

Performing Arts Graduate Program Journal, University of

Campinas

do tempo, as duas linhas de movimento foram se distanciando e assumindo suas identidades próprias:

- O jazz dance, como notamos hoje, foi amplamente abraçado pelas artes performativas e pelas escolas de dança, possibilitando um desenvolvimento estético e técnico mais tradicional deste estilo de dança. De acordo com Marcela Benvegnu, nos anos 1920:

A dança negra começou a adaptar-se às características técnicas conhecidas, derivadas dos bailes africanos (já modificada pelos brancos), caracterizando o jazz como uma dança que usa o isolamento de partes do corpo que se movem separadamente seguindo o mesmo ritmo - swing; movimentos rítmicos sincopados, uso da polirritmia combinação do corpo em vários ritmos diferentes - e o uso correto do centro da gravidade do corpo que dança (2011, p. 56).

- O sapateado, por sua vez, se popularizou por meio dos improvisos, brincadeiras, desafios e das big bands ${ }^{7}$ e, apesar de possuir uma clara codificação técnica, tradicionalmente não se perpetuou por meio dela. No livro Tap Dancing America, a autora Constance Valis Hill fala um pouco sobre:

[...] o sapateado se desenvolveu com as pessoas ouvindo e assistindo uma às outras nas ruas, salões de dança e clubes, onde os passos eram compartilhados, roubados e reinventados. A "técnica" é transmitida visual, oral e corporalmente, em um intercâmbio rítmico entre dançarinos e músicos8 (HILL, 2010, p.3).

As duas formas de dança aqui discutidas se popularizaram no Brasil por volta dos anos 1980, e apesar de terem sido influenciadas pela cultura e sociedade do país, mantiveram suas raízes firmemente atreladas à história que as constituiu como estilos.

\footnotetext{
7 Big bands são grandes grupos instrumentais ligados ao jazz music, surgidos e reconhecidos na Era do Swing, entre os anos de 1920 e 1950, nos Estados Unidos.

8 " [...] tap dance developed from people listening to and watching each other dance in the street, dance hall, or social club, where steps were shared, stolen and reinvented. "Technique" is transmitted visually, aurally and corporeally, in a rhythmic exchange between dancers and musicians".
} 
Conceição | Conception

Revista do Programa de Pós-Graduação em Artes da

Cena, Universidade Estadual de Campinas

Performing Arts Graduate Program Journal, University of

Campinas

Após este panorama, pretendo expor a seguir duas diferentes formas de trabalhar técnica e criatividade: de um lado o jazz dance com o foco voltado para uma formação mais tecnicista, observado na Anacã Cia de Dança, e do outro lado o tap dance com o foco na formação criativa/sensível do bailarino, identificado na Dorrance Dance.

Apresentação das companhias de dança e seus processos criativos

\section{- Anacã Cia de Dança}

Fundada em 2012 pelo grande nome do jazz dance no Brasil, Edy Wilson de Rossi, a Anacã Cia de Dança é uma companhia estável com sede num estúdio com o mesmo nome situado em uma área nobre da cidade de São Paulo. Com grande influência da dança contemporânea e do balé clássico, o diretor e coreógrafo trabalha com uma rígida clareza e unidade visual e uma técnica que busca qualidade além do que chamaria de refinada. A tradição gestual e de movimentos que significam o mundo deste estilo de dança faz-se presente nas composições da companhia. Seus processos criativos brotam na maioria das vezes do desejo de criar uma dança inspirada em histórias, contos e vivências que estejam em latência e em diálogo com o contexto social e político do nosso país. É possível enxergar por entre os virtuosos passos um universo de possíveis significações e uma multiplicidade de entendimentos, mesmo que ainda restritos a um tema proposto e apresentado desde o início.

As movimentações do último trabalho da companhia, EleEEla, trazem ao palco um vocabulário jazzístico, que ainda que bastante desconstruído pelo enredo contemporâneo proposto, permite ao público embrenhar-se pela dualidade e sensualidade desse estilo de dança. Pensando o centro do corpo como gerador de 
Conceição | Conception

Revista do Programa de Pós-Graduação em Artes da

Cena, Universidade Estadual de Campinas

Performing Arts Graduate Program Journal, University of

Campinas

pré-movimentos ${ }^{9}$, as dinâmicas e tonicidades específicas desse estilo de dança afloram por entre os giros, saltos e extensões apuradamente realizados pelos bailarinos.

A figura do primeiro bailarino das companhias de balé clássico é dissolvida entre os bailarinos mais antigos da Anacã Cia de Dança. Eles não só protagonizam os espetáculos, como também são responsáveis pela proposição de movimentações que darão origem aos trabalhos. Esses dois ou três profissionais que estão há mais tempo na companhia respondem a estímulos e esboços de movimentos dados pelo diretor e coreógrafo, até chegarem a uma dança específica que traduza a ideia da coreografia a ser desenvolvida. Após muitos momentos de experimentação e composição, o produto dos laboratórios é levado para os outros membros da companhia e, em pouco tempo, o repertório já é conhecido por todos.

\section{- Dorrance Dance:}

Criada em 2010 pela renomada sapateadora Michelle Dorrance, a companhia explora em seus trabalhos primordialmente as características do som (intensidade, altura, duração e timbre) produzidos pelos sapatos de sapateado e sua acentuação e dinamização realizadas a partir dos impulsos corporais. A visão do sapateador como bailarino e musicista traz para as composições de Dorrance uma preocupação com a combinação dos sons e a organicidade do corpo, com o som a ser visto e o movimento a ser ouvido. Em entrevista, Dorrance nos fala sobre a integração entre música e dança:

Acredito que o tap dance seja a mais suprema forma de manifestação artística. Ser capaz de atuar como dançarino e musicista ao mesmo tempo, nada se compara a isso... Tem algo que é realmente orgânico em um simples toque dos pés no chão. Tem algo orgânico em nossos biorritmos, nas batidas dos nossos corações. E ser capaz de demonstrar esse interior através de uma forma em movimento, é

\footnotetext{
9 Atitudes em relação ao peso e a gravidade, que existem antes mesmo de se iniciar o movimento. Produzem a carga expressiva do movimento a ser executado (GODARD, 2001,p. 13).
} 
Conceição | Conception

Revista do Programa de Pós-Graduação em Artes da

Cena, Universidade Estadual de Campinas

Performing Arts Graduate Program Journal, University of

Campinas

fenomenal (DORRANCE, $2015 \mathrm{~s} / \mathrm{p}) \cdot{ }^{10}$

A composição musical é o ponto de partida para os trabalhos de Dorrance. A partir de estudos de ritmos compostos e tonalidades de sons, foi criado, juntamente com seus bailarinos/sapateadores/musicistas, o show ETM: Double Down (2016), último trabalho estreado pelo grupo. Com ajuda de sensores eletrônicos super sensíveis e uma genialidade fora do comum, é criada uma melodia percussiva que envolve os corpos em movimento durante toda a apresentação. A proposta e resposta de cada sapateador sobre a música produzida por eles próprios cria uma atmosfera comum e uma total não uniformidade aos olhos do espectador. A preocupação com o timbre, altura, vibração, andamento e intensidade dos sons acaba por ser o maestro dos movimentos e a técnica do sapateado, ainda que muito presente, não se torna estrela da peça.

Os bailarinos que participam do espetáculo possuem uma técnica muito bem lapidada e uma grande segurança com improvisações, o que lhes possibilita brincar com os passos sem escapar da estrutura coreográfica. Nessa obra, os códigos e passos servem como ferramentas para atingir o pensamento rítmico e sonoro, o que exige um conhecimento largo sobre a técnica em si, mas deixa aberto um espaço de proposição e exploração de movimentos. A acentuação dos passos, que influencia diretamente na composição musical, é o principal motivo para o estabelecimento de direções, níveis e tônus. A precisão e especificidade da movimentação corporal dos sapateadores se dá pela clareza de intenções gestuais em cada bloco coreográfico. Nos ensaios, a partir do que os sapateadores propõem, a diretora e coreógrafa verticaliza essas intenções de forma a dar sentido à obra em processo.

\footnotetext{
10 "I think tap dance is the ultimate art form, at least for me, To be able to be a dancer and a musician at the same time, there's nothing like it. ... There's something that's really organic in your footfall. There's something organic in your biorhythms, your heartbeat. And to be able to demonstrate that inside of a moving form is phenomena" (Michelle Dorrance em entrevista para National Public Radio, em 2015).
} 
Conceição | Conception

Revista do Programa de Pós-Graduação em Artes da

Cena, Universidade Estadual de Campinas

Performing Arts Graduate Program Journal, University of

Campinas

Técnica $x$ criatividade: uma breve análise sobre os processos criativos

A partir dos processos acima descritos, foi possível desenvolver um pensamento crítico sobre as duas possíveis formas apresentadas de ensinar e criar dentro das companhias pesquisadas.

Através da cópia e da busca pelo ideal proposto, pude perceber que a personalidade dos bailarinos pode facilmente se perder em meio à responsabilidade de reproduzir com maestria tudo o que é passado. A imagem de bailarinos principais causa um rebuliço na própria autoimagem dos demais e a preocupação com a forma acaba, na maioria das vezes, por minar o potencial de expressão individual de bailarinos "não criadores". Forma-se, assim, um exército bem treinado a perpetuar passivamente uma estética desprovida de caráter transformador.

No entanto, não se pode negar que para a realização de composições, obras e trabalhos de dança, a necessidade de um profundo conhecimento da área é essencial. Inclusive, pode-se afirmar que um espaço de abstração e a criação do novo só podem surgir a partir de uma base muito bem fundamentada a ser continuamente explorada e repensada, abrindo espaço para reconfigurações do próprio fazer. A técnica e o pensamento estrutural construídos no espetáculo da Anacã Cia de Dança, por exemplo, se mostram extremamente eficazes na construção de um fio condutor que ligue propostas claras, amplas e profundas, dando sentido à produção.

Nas aulas de dança com ênfase exclusiva no aprimoramento técnico as vozes do "dançar" tornam-se ausentes, aquilo que vai além dos corpos preparados tecnicamente não tem importância, não existe. (MARQUES, 2010, p. 33-34)

Em termos de processo em ambas as companhias observadas, acredito que o envolvimento dos intérpretes na criação da obra seja, portanto, essencial para propiciar um total engajamento corporal e mental. E isso se reflete na integridade artística e na criação de uma identidade própria daquilo que está sendo apresentado; possibilita a revisitação de uma técnica antiga, que é relida historicamente, revista 
Conceição | Conception

Revista do Programa de Pós-Graduação em Artes da

Cena, Universidade Estadual de Campinas

Performing Arts Graduate Program Journal, University of

Campinas

esteticamente e reinterpretada sensivelmente de forma a dialogar com a atualidade em termos sociais, políticos e culturais. A multiplicidade de significados permitida pelo espetáculo de Dorrance, por exemplo, cria uma percepção que transborda os limites de identificação técnica do tap dance por si só. E além da cumplicidade que passa a existir entre os bailarinos e a coreógrafa pelo fazer conjunto, o público é convidado a fazer sua própria leitura dentro do contexto proposto.

Para além das criações artísticas dentro das companhias, acredito que os processos de ensino e aprendizagem que se dão durante a elaboração destas criações são os principais responsáveis pela formação de cidadãos críticos e íntegros. As histórias e trajetórias individuais de cada bailarino profissional, quando reconhecidas nesses processos, propiciam um maior engajamento com o trabalho. Todas as suas viáveis interpretações e significações, passam a ser, então, muito mais palpáveis, criando identificações e possibilitando que o público seja efetivamente afetado pelo que está assistindo.

Após refletir sobre o trabalho em processo, construído e apresentado por essas companhias profissionais, pude perceber a potência que existe na arte quando produzida em confluência com os conceitos trazidos do campo das pedagogias da dança. Durante meu percurso como professora, procurei abrir caminhos para que esses conceitos aflorassem por meio do movimento. As formas de ensinar, tendo em vista todo esse universo criativo/sensível, foram para mim transformadoras. Encontrei um lugar de troca e experimentações com meus alunos, em que eles próprios se permitiram descobrir suas vozes por meio da dança, principalmente nas aulas de sapateado.

Dentro desse todo, o movimento deixa de ter sua importância vinculada apenas ao condicionamento físico, e assume um lugar de forma de expressão artística. O fazer técnico e o artístico articulam-se de maneira a potencializar as criações em dança, pelo encontro de ideais sensíveis e estéticos. E o estabelecimento de um diálogo entre o que é produzido e a realidade da sociedade em que estamos inseridos torna-se, portanto, essencial para que se assuma, finalmente, a dança como 
Conceição | Conception

Revista do Programa de Pós-Graduação em Artes da

Cena, Universidade Estadual de Campinas

Performing Arts Graduate Program Journal, University of

Campinas

linguagem corporal, como forma de transmissão de conhecimento e como transformadora das diversas existências humanas e de pensamentos. A escolha consciente do modo como resolvemos trabalhar com todos esses pressupostos acaba por configurar a liberdade do fazer dança dos dias de hoje. A preciosidade dessa forma de manifestação, comunicação e expressão por meio da arte, se dá exatamente nas relações criadas entre ações, atores e espaços envolvidos, que geram entre si pensamentos, críticas, reflexões e, portanto, transformações do próprio universo por estes habitado.

\section{REFERÊNCIAS}

BENVEGNU, Marcela. Reflexões sobre jazz dance: identidade e (trans) formação. Sala Preta, v. 11, n. 1, p. 53-64, 2011.

DE SOUZA, Ana Paula Abrahamian. Formação do professor de dança: como formar "professores profissionais?" GELEWSKI, Rolf; VER, Ouvir. Estruturas Sonoras 1. Salvador: Nós Editora, 1973.

GELEWSKI, Rolf. Rítmica Métrica, um método didático para o ensino de rítmica. Salvador: Edição da UFBA, v. 37, 1967.

GELEWSKI, Rolf. Da unidade do espaço: algumas reflexões. Universitas, n. 5, 2007.

GELEWSKI, Rolf. Estudo básico de formas. Salvador - BA: Universitas Universidade Federal da Bahia, 1971.

GODARD, Hubert. Gesto e percepção. In Lições de dança 3. Rio de Janeiro: UniverCidade (2001).

GUALDA, Luciana Rosa; DE ARAGÃO SADALLA, Ana Maria Falcão. Formação para o ensino de dança: pensamento de professores. Revista Diálogo Educacional, v. 8, n. 23, p. 207-220, 2008.

HILL, Constance Valis. Tap dancing America: A cultural history. Oxford University Press, 2014. 
Conceição | Conception

Revista do Programa de Pós-Graduação em Artes da

Cena, Universidade Estadual de Campinas

Performing Arts Graduate Program Journal, University of

Campinas

JONHSON, Don. Corpo. Tradução de Adauri Bastos. Rio de Janeiro: Nova Fronteira, 1990.

LEITURAS, S. M. E. Notas sobre a experiência e o saber de experiência. 2000.

MAÇANEIRO, Sheila Mara. A formação do licenciado em dança: saberes multifacetados. Disponível em:

http:/ / www.fap.pr.gov.br/arquivos/File/extensao/1EncontroGrupoPesquisaArteE ducacaoFormacaoContinuada/11ScheilaMaraMacaneiro.pdf Acesso em 29/08/2016.

MARQUES, Isabel A. Dança-educação ou dança e educação? Dos contatos às relações. Algumas perguntas sobre dança e educação. Joinville: Nova Letra, 2010.

ROCHA, Tereza. A dança depois da universidade, e agora?. In: TOMAZZONI, A., WOSNIAK,C., MARINHO,N. Algumas perguntas sobre dança e educação. Joinville: Nova Letra, 2010.

PASSOS, J. C. Rolf Gelewski e as inter-relações entre forma, espaço e tempo: uma proposta pedagógica de improvisação para processos criativos em dança. Anais do I Seminário de Pesquisas do Programa de Pós-Graduação em Artes da Cena. Campinas, Unicamp, 2013. Disponível em:

https://www.publionline.iar.unicamp.br/index.php/ppgadc/article/view/491/45 4

RODRIGUES, Graziela; CONSOLAÇÃO, M.; TAVARES, G. C. F. Mudanças na imagem corporal de bailarinas que vivenciaram o método BPI. Revista Repertório: Teatro e Dança. Ano 13. Número 14. 2010.

SIQUEIRA, D.C.O. Corpo, comunicação e cultura: a dança contemporânea em cena. Campinas: Autores Associados, 2006.

STRAZZACAPPA, Márcia. A tal "Dança Criativa": afinal, o que dança seria?. Airton Tomazzonni, Cristiane Wosniak, Nirvana Marinho (Org.). Seminários de Dança: algumas perguntas sobre dança e educação. Joinville: Nova Letra, 2010.

STRAZZACAPPA, Márcia. Reflexões sobre a formação profissional do artista da dança. In: Lições da Dança. v. 4. Rio de Janeiro: UniverCidade, 2003.

SOUZA, Maria Inês Galvão. O ensino da dança na escola: técnica ou criatividade? Cadernos de Formação RBCE, v. 2, n. 1, 2011. 
Conceição | Conception

Revista do Programa de Pós-Graduação em Artes da

Cena, Universidade Estadual de Campinas

Performing Arts Graduate Program Journal, University of

Campinas

SUQUET, Annie. Cenas. O corpo dançante: um laboratório da percepção. In: COURTINE, Jean-Jacques (dir.). História do Corpo vol. 3: As mutações do olhar. $\mathrm{O}$ século XX. Petrópolis, RJ: Editora Vozes, 2008.

TERRA, Ana. Onde se produz o artista da dança. TOMAZZONI, A., WOSNIAK, C. \& MARINHO, N. Algumas perguntas sobre dança e educação. Joinville: Nova Letra, 2010.

TEIXEIRA, A., NAVAS, C. Dança Contemporânea. Disponível em: http:/ / www.sesctv.org.br/revista.cfm?materia_id=53_Acesso em: 01/04/2016.

VIANNA, K. A Dança. 4ed. São Paulo: Summus, 2005. 